\title{
Evolution of Pediatric Cardiology over the Last 50 Years - Part III
}

\section{P Syamasundar Rao, MD*}

\section{Professor of Pediatrics and Medicine, Division of Pediatric Cardiology, Department of Pediatrics, Emeritus Chief of Pediatric} Cardiology, Children's Memorial Hermann Hospital, University of Texas-Houston McGovern Medical School, USA

*Corresponding author: P Syamasundar Rao, MD, Professor and Emeritus Chief of Pediatric Cardiology, Division of Pediatric Cardiology, Department of Pediatrics, Children's Memorial Hermann Hospital, University of Texas-Houston McGovern Medical School, 6410 Fannin, UTPB Suite \# 425, Houston, Texas, 77030, USA, Tel: 713-500-5738, Fax: 713-500-5171

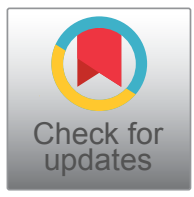

\section{Introduction}

The author has just written a book on the evolution of the specialty of Pediatric Cardiology over the last 50 years [1]. The intent of this review is to present a summary of this book. Because of large amount of this material, the review is separated into four parts. In these first and second parts, transcatheter interventions (balloon angioplasty/valvuloplasty procedures and percutaneous occlusions) were appraised. In this paper, electrocardiography, echocardiography, and cardiac catheterization will be reviewed.

\section{Electrocardiography}

In this review, contributions of the author pertaining to electrocardiography were examined. These contributions were: A study of normal Frank and McFee vectorcardiograms in the normal adolescent [2], distinguishing right ventricular hypertrophy from postero-basal left ventricular hypertrophy [3], identifying possible cause of alternating failure of mechanical to electrical depolarization (AFORMED) phenomenon [4], examination to see if racial variations in electrocardiograms and vectorcardiograms between black and white children exist and if so, the causes of such variation $[5,6]$, document resolution with medications of congestive cardiomyopathy due to chronic tachycardia (Figure 1) [7], changes in the electrocardiogram (ECG) after balloon pulmonary valvuloplasty (Figure 2 ) $[8,9]$, utility of electrocardiogram in delineating atrial (Figure 3 ) and ventricular situs in patients with dextrocardia and heterotaxy syndromes [10-14], and an appraisal of arrhythmias in children [15-17].
Documentation of diagnosis of Ebstein's anomaly of the left atrioventricular valve with congenital corrected transposition of the great arteries by intracavitary electrocardiography [18], ECG features of tricuspid atresia $[19,20]$ and etiology of left axis deviation in patients with tricuspid atresia [19-21] were also presented.

\section{Echocardiography}

To a large extent, the author has self-learned the echocardiography and Doppler recording techniques as well the skills of interpretation of such recordings; these endeavors helped the author to participate and perform several echocardiographic investigations. The echo studies include, usefulness of echocardiography in estimating the magnitude of left-to-right shunt in isolated ventricular septal defects (VSDs) (Figure 4) [22], usefulness of contrast echocardiography in the diagnosis of anomalous drainage of the right superior vena cava to the left atrium (Figure 5) [23,24], identification of pitfalls of m-mode echocardiography in the evaluation of the aortic root in left ventricular hypoplasia syndromes [25].

Other contributions are: Review of evaluation of left ventricular function by echocardiography $[26,27]$, echocardiographic diagnosis of tricuspid atresia [28], utility of contrast echocardiography in the assessment of hypoxemia after open heart surgery [29], quantifying left ventricular muscle mass by m-mode echocardiograms in children [30], racial and sexual differences in echo measurements in children [31], heart size and function in children with sickle cell disease [32], and after-

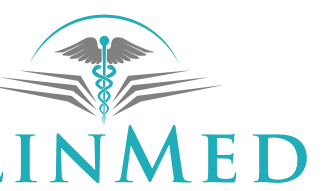

INTERNATIONAL LIBRARY

Citation: Rao PS (2021) Evolution of Pediatric Cardiology over the Last 50 Years - Part III. Int J Clin Cardiol 8:225. doi.org/10.23937/2378-2951/1410225

Accepted: May 12, 2021: Published: May 14, 2021

Copyright: (c) 2021 Rao PS. This is an open-access article distributed under the terms of the Creative Commons Attribution License, which permits unrestricted use, distribution, and reproduction in any medium, provided the original author and source are credited. 


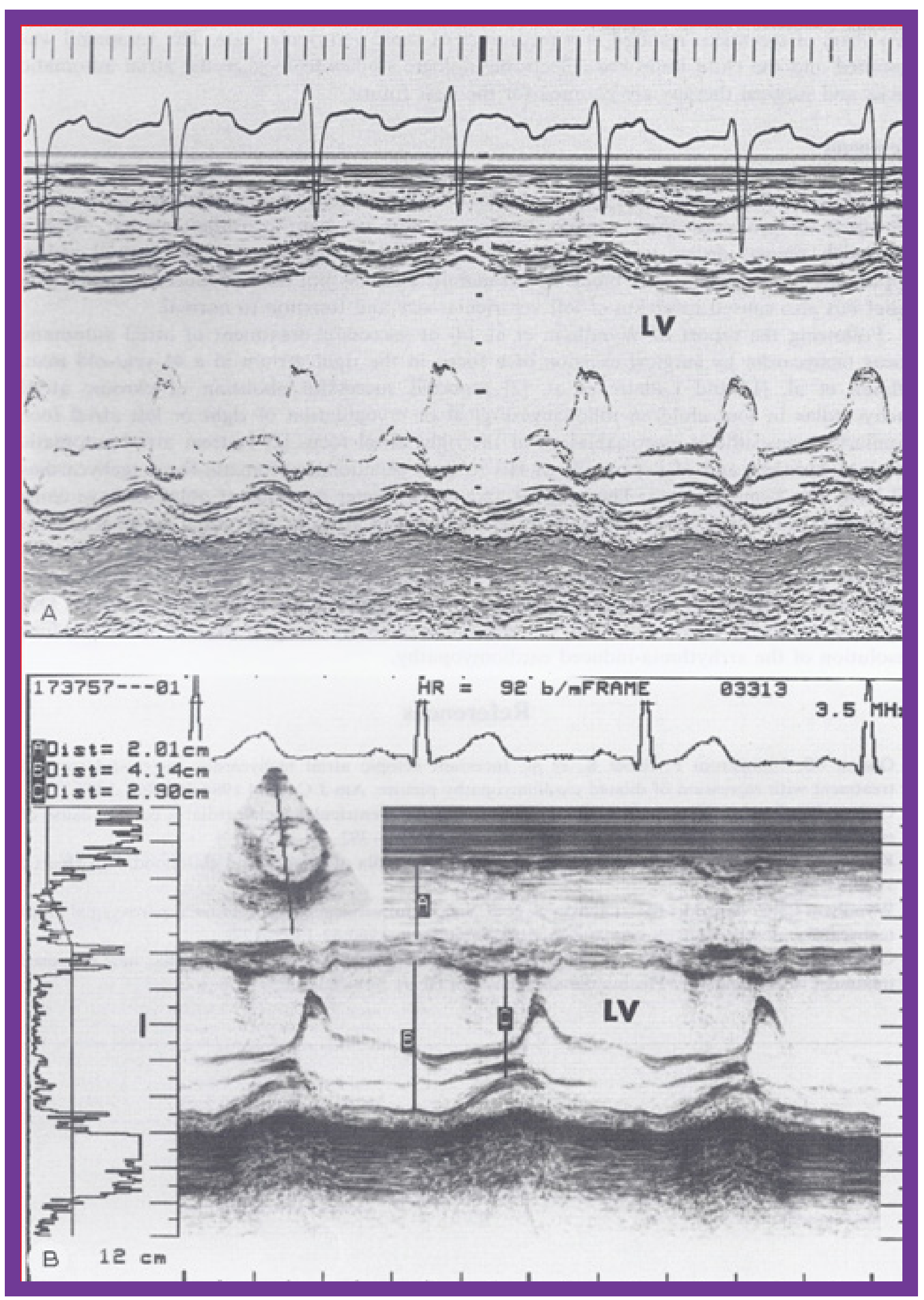

Figure 1: A) M-mode echocardiogram of a 3-year-old child who developed arrhythmia-induced cardiomyopathy; note the markedly dilated left ventricle (LV) with poor function (calculated shortening fraction was 13\%). B) M-mode echocardiogram (5.5 years later) of the same patient following successful drug therapy; note the normal-sized LV with normal function (calculated shortening fraction was $29 \%$ ) [7]. 


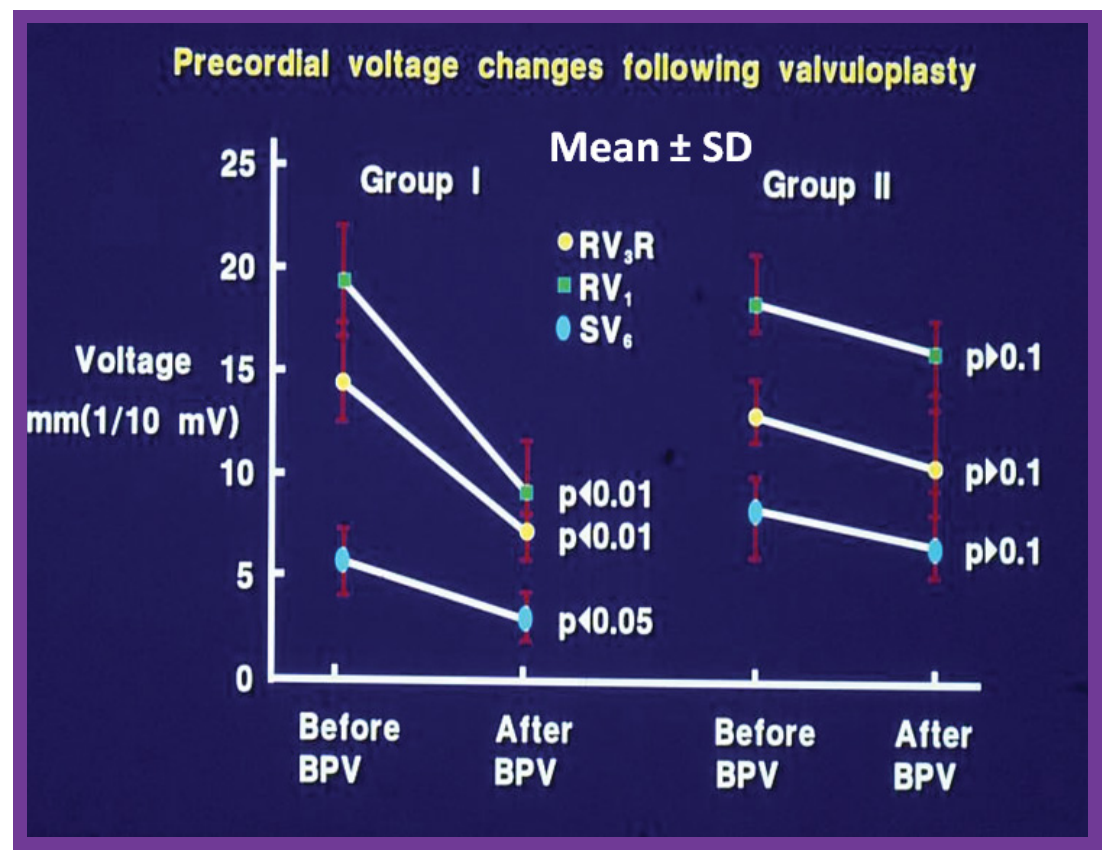

Figure 2: Precordial ECG voltages ( $R$ waves in leads $V_{3} R$ and $V_{1}$ and $S$ waves in $V_{6}$ ) prior to and at follow-up after balloon pulmonary valvuloplasty (BPV) in group I (with good results) (left panel) and group II (with poor results) (right panel) are depicted. The mean and standard deviation (SD) are shown. Note the significant $(p<0.05$ to 0.01$)$ decrease in the voltages in group I while there was no significant $(p>0.1)$ change in group II [9].

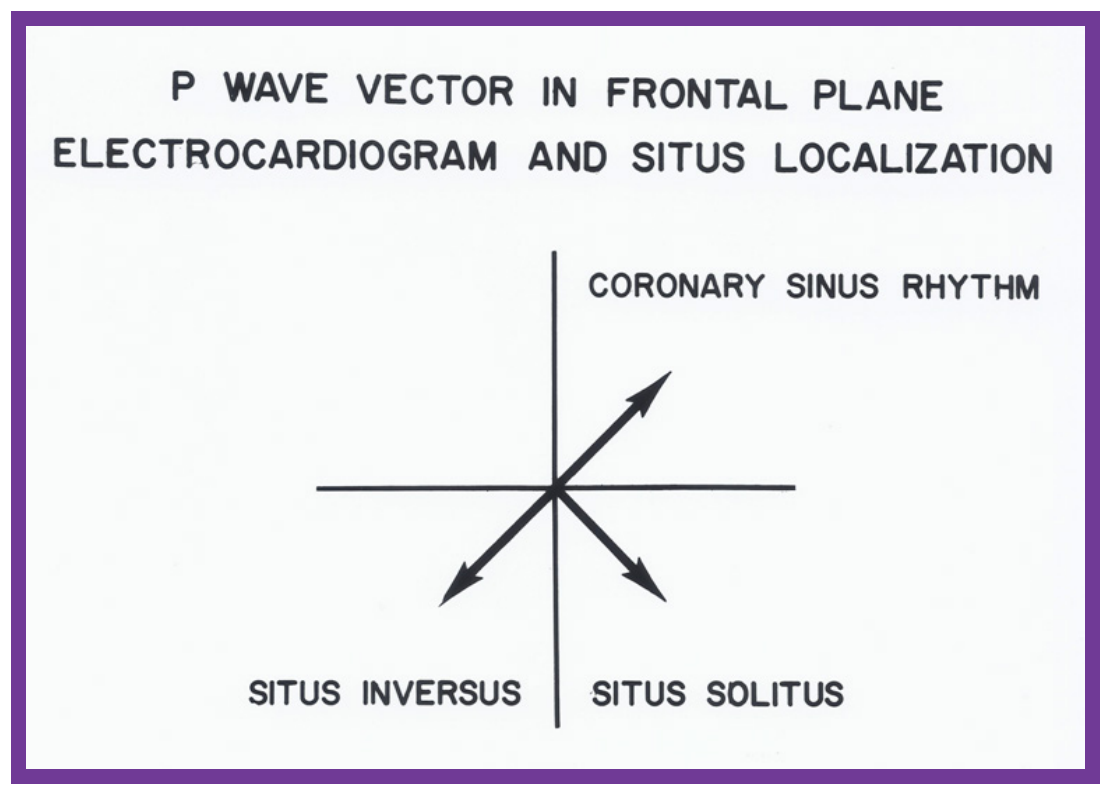

Figure 3: The location of the $P$ vector (axis) in the frontal plane is shown for situs solitus $\left(+45^{\circ}\right)$ and situs inversus $\left(+135^{\circ}\right)$. A P vector between $0^{\circ}$ and $-90^{\circ}$ is called coronary sinus rhythm and is not helpful in atrial situs assignment [10]. 


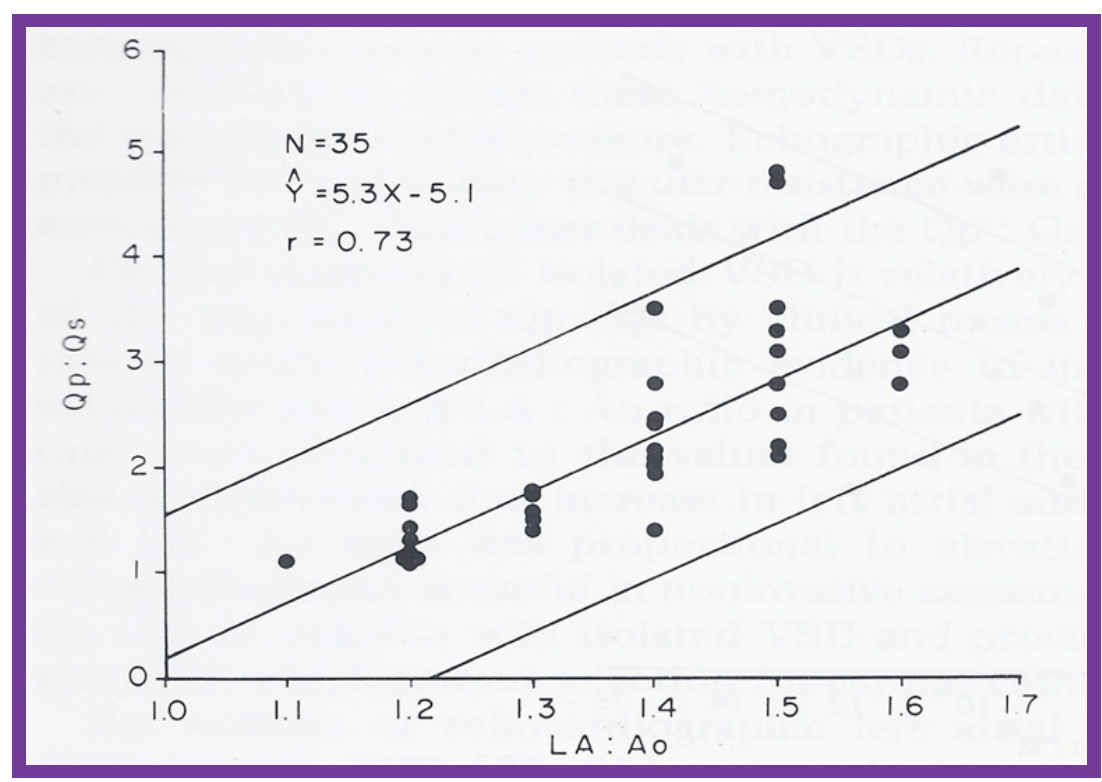

Figure 4: Scattergram demonstrating the relationship of the left atrium to aortic root ratio (LA:Ao) with the pulmonary-tosystemic flow ratio (Qp:Qs) in patients with isolated ventricular septal defects. The central line is the regression line and the parallel lines demarcate the confidence interval. The number of patients $(\mathrm{N})$, regression equation and correlation coefficient (r) are shown in the insert at the top left [22].

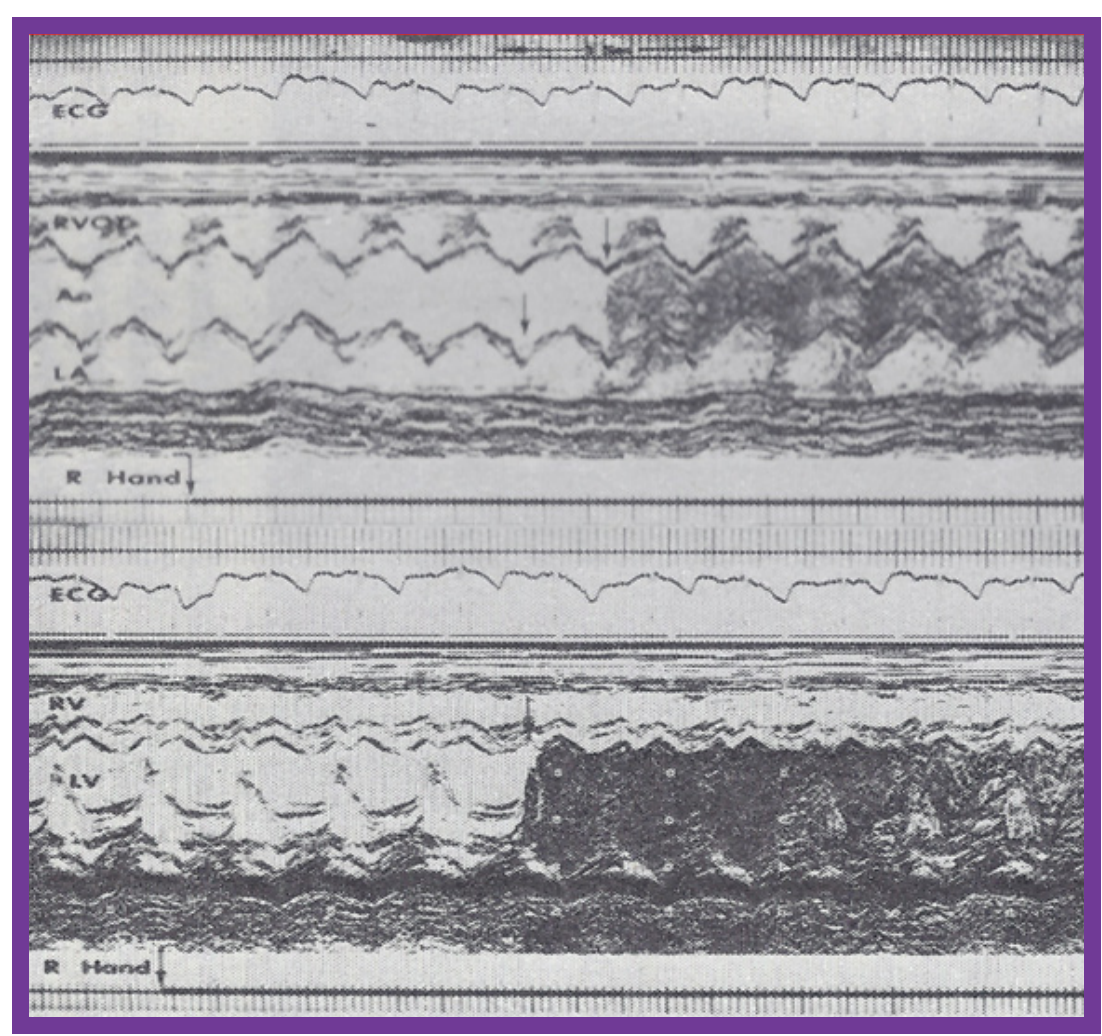

Figure 5: A) Selected M-mode recordings from the parasternal short axis view of the left atrium (LA), aorta (Ao), and right ventricular outflow tract (RVOT), made while injecting agitated saline into veins of the right (R) hand, which demonstrate the appearance of contrast echoes in the LA (arrow) first and then the Ao (arrow); B) Similar tracings of the left ventricle (LV) and right ventricle (RV) demonstrate the appearance of contrast echoes in the LV (arrow) without contrast in the RV. Similar findings were seen while injecting agitated saline into the veins of the left hand. These recordings indicate the drainage of the superior vena cava into the left atrium. The start of the agitated saline injection is marked with arrows at the bottom of each tracing. ECG: Electrocardiogram [23]. 


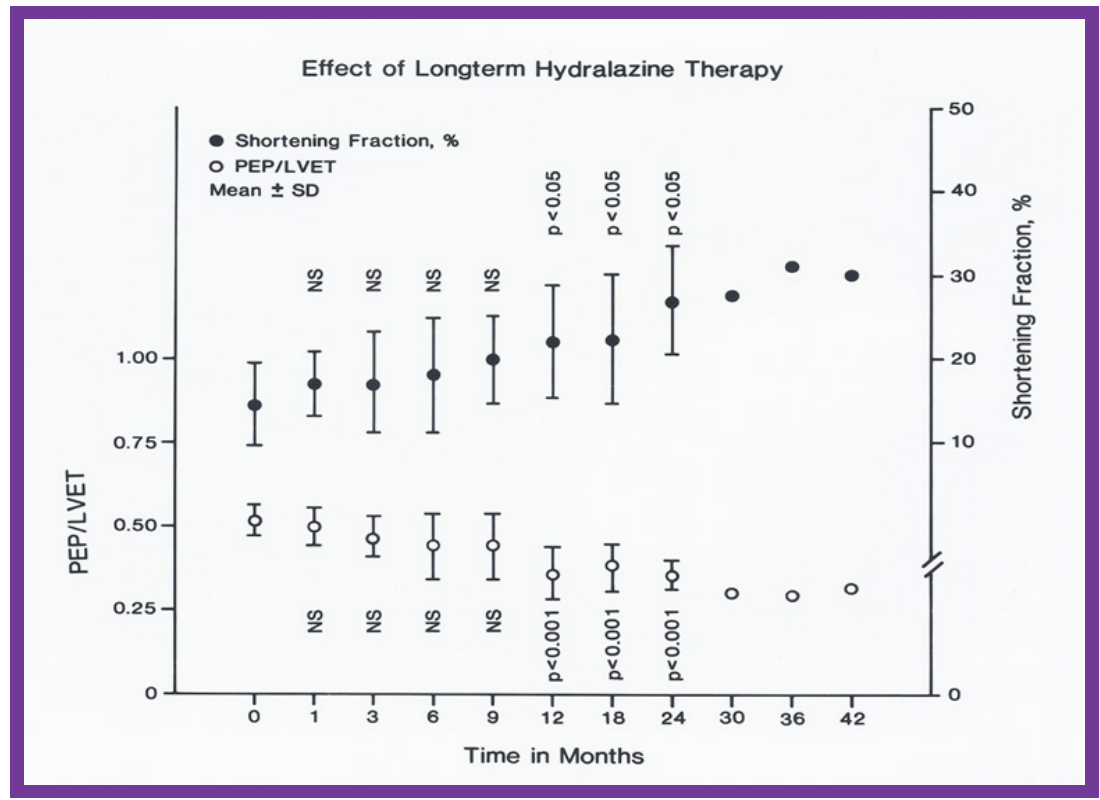

Figure 6: Pre-ejection period (PEP)/left ventricular ejection time (LVET) ratio (open circles) and shortening fraction in percent (\%) (closed circles) are shown from prior to the start of hydralazine therapy (0) and at 1, 3, 6, 9, 12, 18, 24, 30, 36 and 42 months following its initiation. The means and standard deviations (SD) are shown. The number of subjects at 30,36 and 42 months is small and therefore, only the mean values are shown. Note the gradual improvement in PEP/LVET ratio and shortening fraction. A statistically significant $(p<0.05$ to $<0.001)$ change becomes apparent from the 12-month follow-up onwards [33].

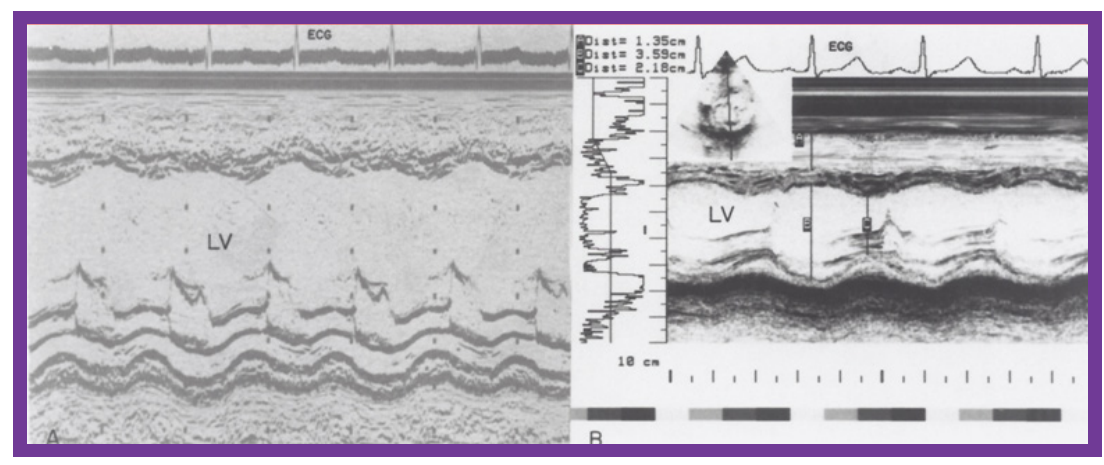

Figure 7: A) Selected M-mode recordings from the parasternal short axis view of the left ventricle (LV) made prior to and B) following hydralazine therapy. Note a significant improvement in the LV size and function [1].

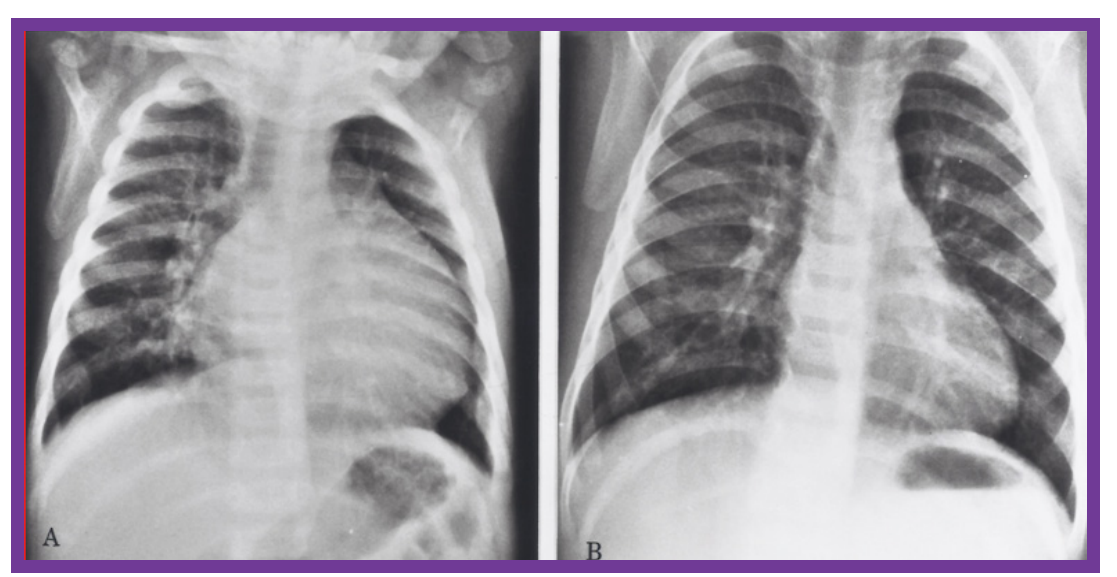

Figure 8: Chest X-rays in antero-posterior view, prior to A) and following B) Hydralazine therapy. A) Moderate cardiomegaly and pulmonary venous congestion were seen prior to therapy; B) Which improved remarkably after therapy [1]. 
load reduction in the treatment of primary myocardial disease (Figure 6, Figure 7 and Figure 8) [33].

Also reviewed were usefulness of echo-Doppler studies in the assessment of the results of balloon pulmonary valvuloplasty [34], utility of Doppler studies in the estimation of pressure gradients across the pulmonary valve in pulmonary stenosis [35], appraisal of Doppler echocardiography in non-invasive diagnosis of heart disease in children [36], echo-Doppler studies in the appraisal of the results of balloon procedure for coarctation of the aorta (Figure 9) [37], importance of Dop- pler in the prediction of pressure gradients across aortic coarctation [38], description of foramen ovale and transatrial Doppler velocity patterns in the normal fetus (Figure 10) [39], establishing the correlation of shunt flow and angiographic size to stretched diameter of the atrial septal defect by echocardiograms [40], echocardiographic assessment of balloon-stretched diameter of secundum atrial septal defects [41], development of echocardiographic predictors of success of buttoned device closure of atrial septal defect [42], pointing out of limitations of echo in complete assessment of mixed type of total anomalous pulmonary venous connection

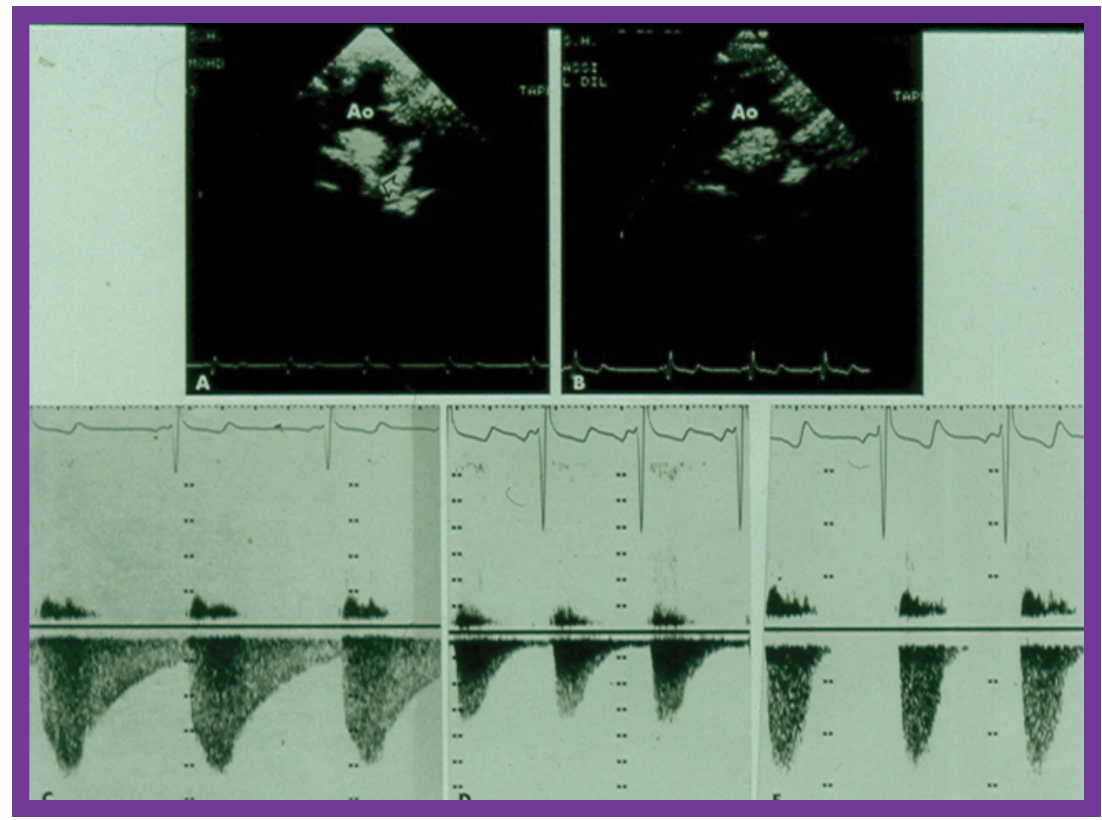

Figure 9: A) Two-dimensional (2D) echo images prior to and; B) following balloon angioplasty of aortic coarctation show improvement in B; C) Continuous wave Doppler flow velocity recordings from suprasternal notch directing the Doppler signal towards the descending aorta prior to and; D) immediately following balloon angioplasty of aortic coarctation and; E) at six months after angioplasty are shown. Note the reduction of peak Doppler flow velocity from $C$ to $D$, with further fall in E. Also note that the diastolic flow is seen throughout the entire diastole (pandiastolic) prior to angioplasty (C), and is seen only is early diastole immediately after angioplasty (D). At six-month follow-up (E), there was no diastolic flow at all [37].

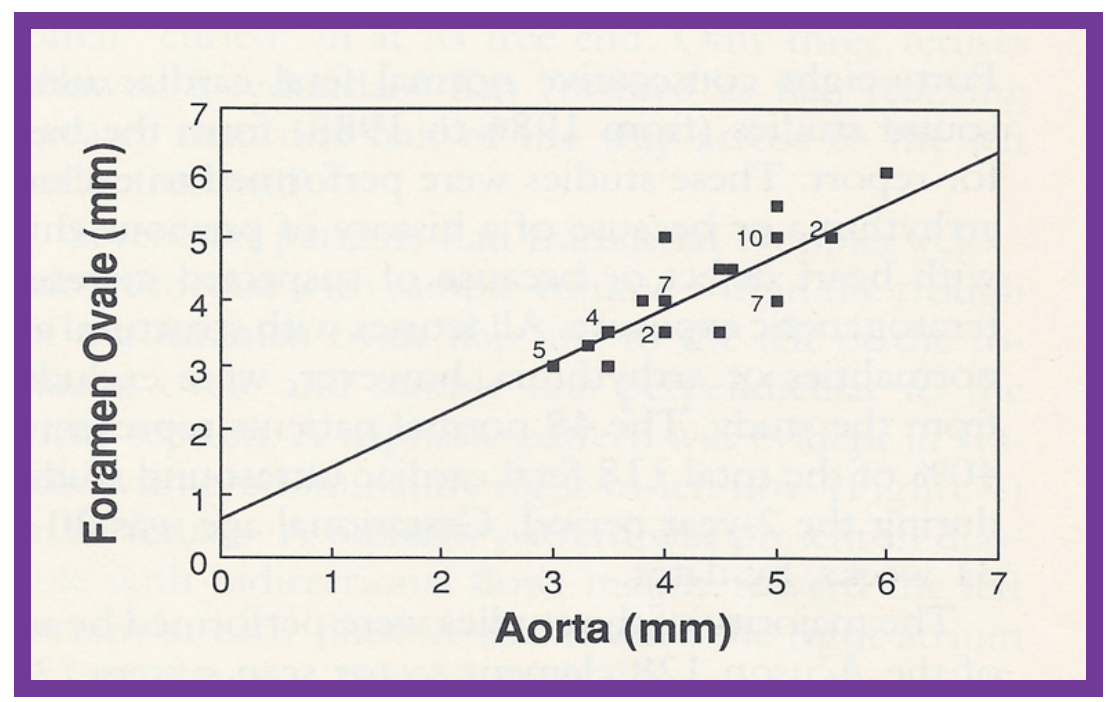

Figure 10: Plot of the diameter of the foramen ovale against the diameter of the aorta. The numbers indicate the number of subjects with that particular measurement. Note the excellent correlation with an $r$ value of $0.84, y$ intercept of 0.605 and slope of 0.817 [39]. 


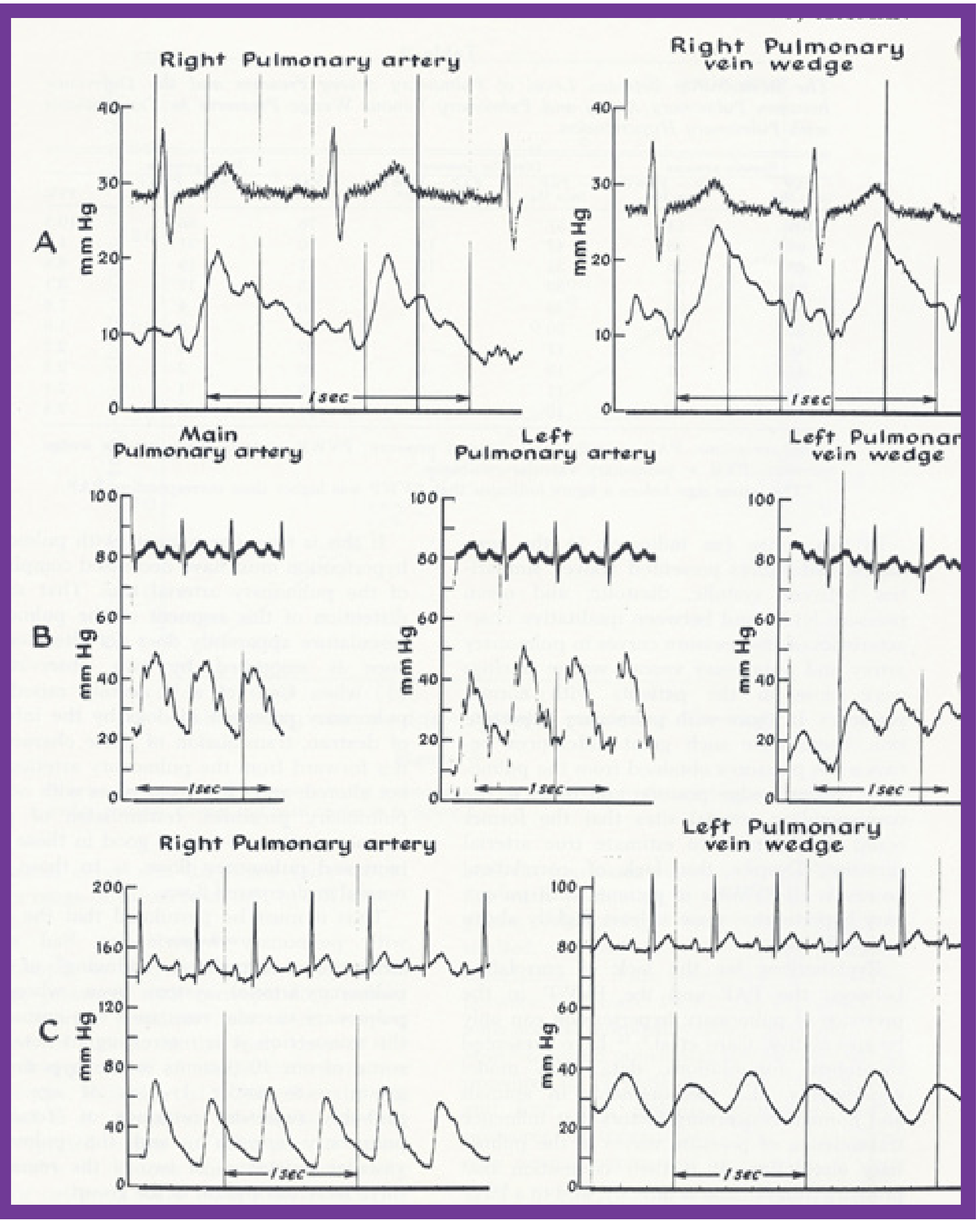

Figure 11: This figure shows examples of pulmonary venous (PV) wedge and the corresponding pulmonary arterial (PA) pressure tracings. Note the similarity of the tracings in patients with normal PA pressures (A and $B)$. In a patient with elevated PA pressure the PV wedge pressures is mildly damped with slightly lower magnitude when compared with the PA pressure (C). The pulse pressure is also lower in the PV wedge position. Note that both the PA and PV wedge pressure tracings demonstrate pulsus alternans in a patient with congestive heart failure (C) [55]. 


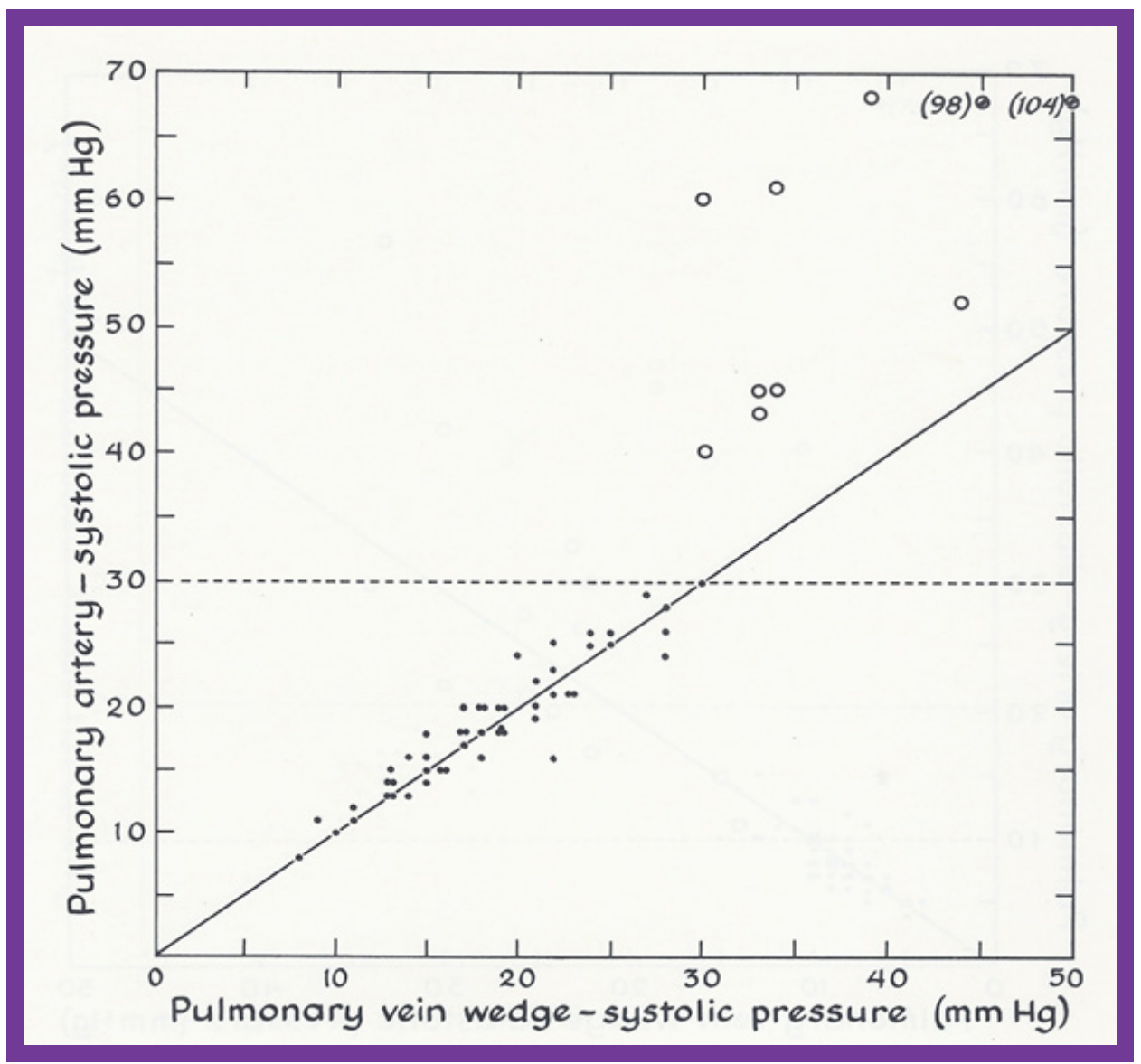

Figure 12: This figure demonstrates the relationship of the pulmonary artery (PA) with the pulmonary venous (PV) wedge systolic pressures. Patients with normal pressures (i.e., less than $30 \mathrm{mmHg}$ ) are shown as closed circles while those with systolic pulmonary hypertension are shown as open circles. Note the close-to-identical PA and PV wedge systolic pressures in patients with normal PA pressures, and the lack of such a relationship in patients with elevated PA pressures. The dashed line across at $30 \mathrm{mmHg}$ represents the upper limits of normal PA pressure. The graphs plotting the diastolic and mean pressures show similar findings; the interested reader is referred to the original publication (Figure 2 and Figure 3) for review [55].

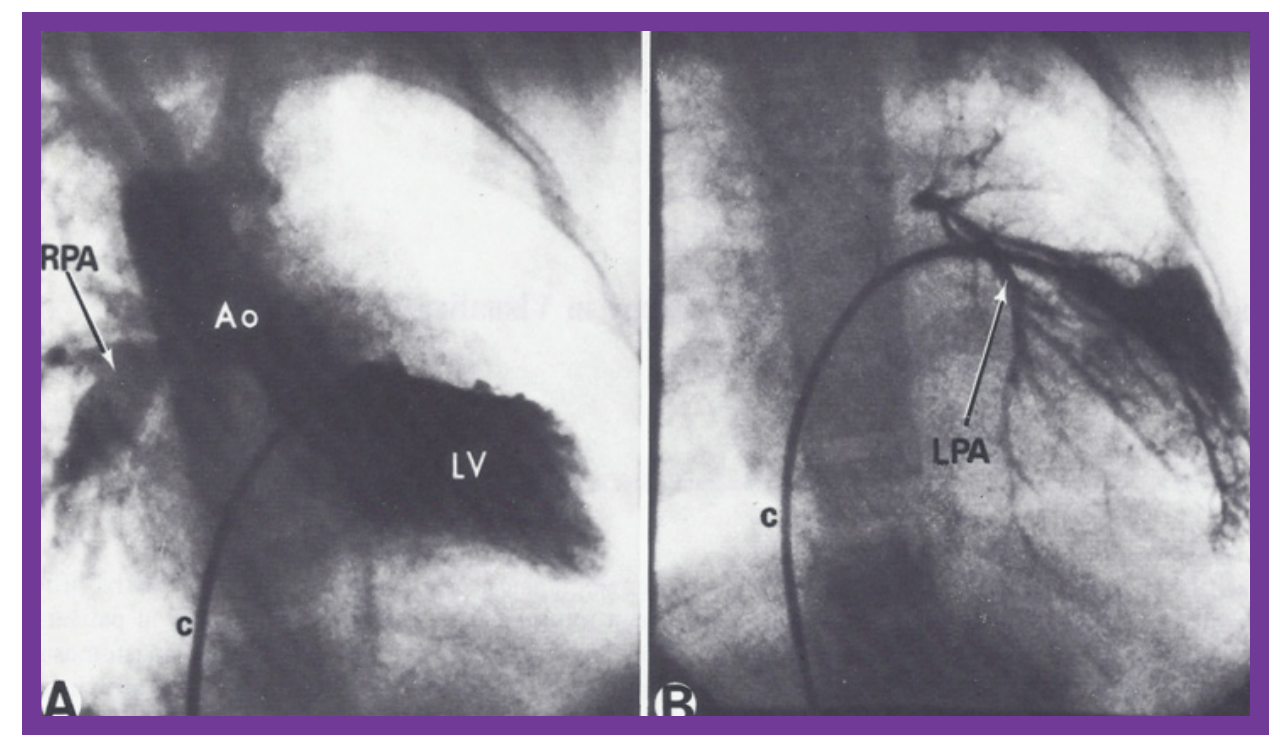

Figure 13: A) Selected frame of a left ventricular (LV) cineangiogram in postero-anterior view, demonstrating the opacification of the aorta (Ao) with a visualization of the right pulmonary artery (RPA) without the opacification of the left pulmonary artery (LPA). The catheter (c) is positioned in the LV via the patent foramen ovale and left atrium (not marked); B) Selected frame of a pulmonary venous wedge cineangiogram, clearly demonstrating the size of the LPA. The catheter is positioned in the pulmonary venous wedge position via the patent foramen ovale and left atrium (not marked) [62]. 
[43], echocardiographic follow-up results of buttoned device occlusion of atrial septal defect [44], review of ultrasound studies [45-47], collaborative echo-Doppler studies [48-50], echocardiographic evaluation of the results of balloon pulmonary valvuloplasty [51], editorials on echo topics, aneurysm of the ventricular septum producing pulmonary outflow tract obstruction in the morphologic left ventricle in corrected transposition of the great arteries [52-54] and echo descriptions of CHDs.

\section{Cardiac Catheterization and Selective Cinean- giography}

The contributions of the author in the procedures of

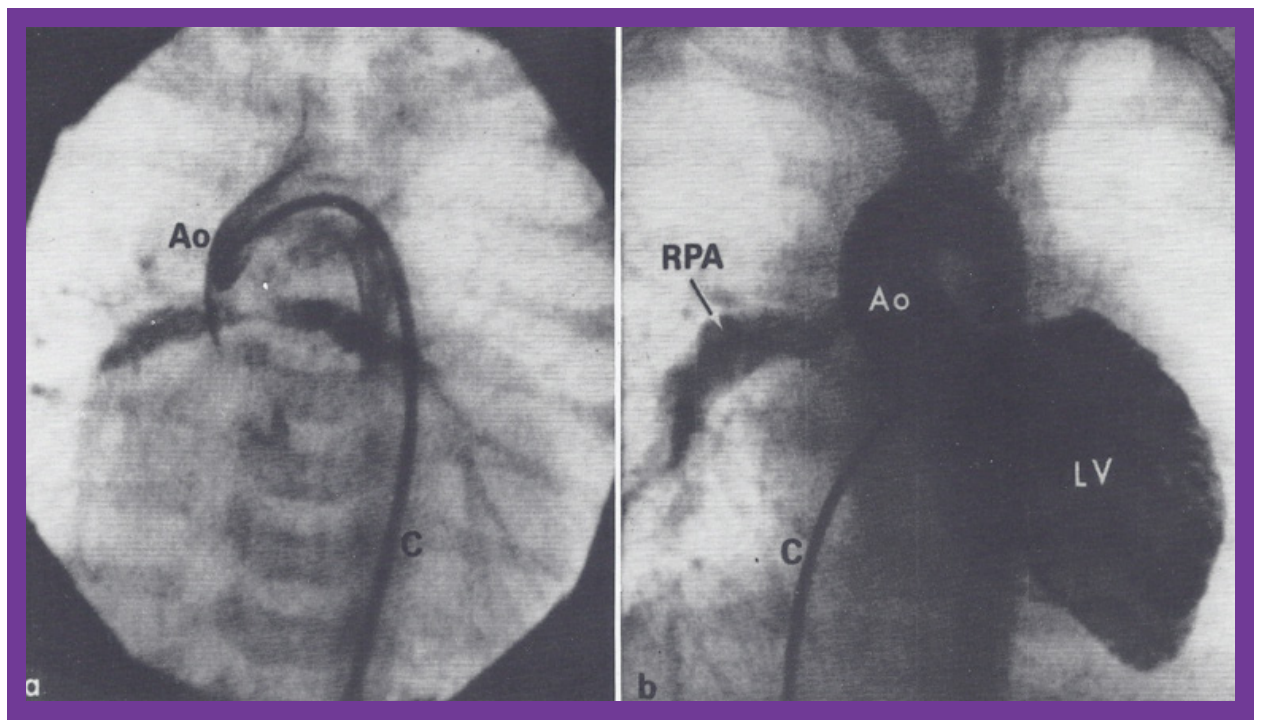

Figure 14: a) Selected frame of an aortic (Ao) root cineangiogram in postero-anterior view, three days after Waterston shunt surgery, demonstrating the prompt opacification of both branch pulmonary arteries via the Waterston shunt. The catheter $(C)$ was positioned in the Ao via the umbilical artery; b) Selected frame of a left ventricular (LV) cineangiogram in postero-anterior view at the age of 12 months, demonstrating opacification of the aorta (Ao) with visualization of the right pulmonary artery (RPA) but without opacification of the left pulmonary artery (LPA). The catheter (c) is positioned in the LV via the patent foramen ovale and left atrium (not marked) [63].

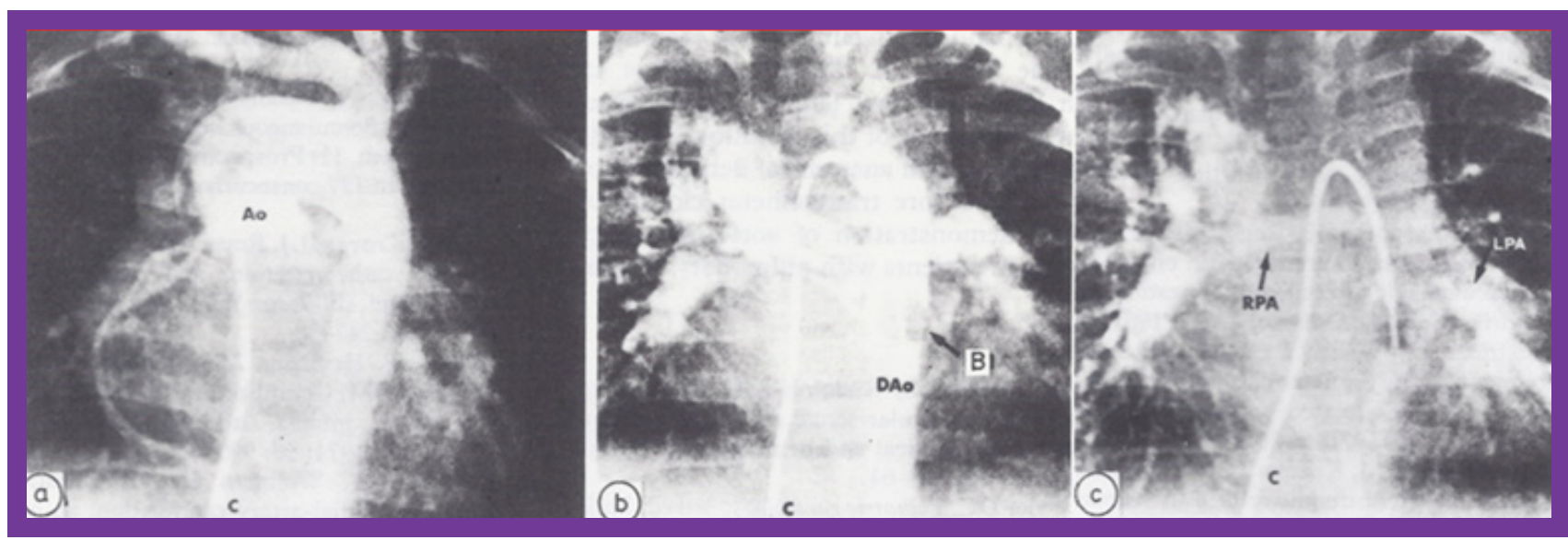

Figure 15: a) Selected frame of an aortic (Ao) root angiogram in postero-anterior view in an infant with tetralogy of Fallot with pulmonary atresia, with multiple aortopulmonary collateral arteries (MAPCAs); the right heart catheter (C) was advanced into the ascending Ao via the VSD. Note that multiple collateral vessels were seen, but there is no clear demonstration of these vessels; b) The same infant's cineangiogram, also in postero-anterior view, obtained by balloon (B) occlusion descending aortography, demonstrates several collateral vessels more clearly than can be seen in a. c) A delayed phase of b demonstrates the right (RPA) and left (LPA) pulmonary arteries. Dao: descending aorta [69]. 


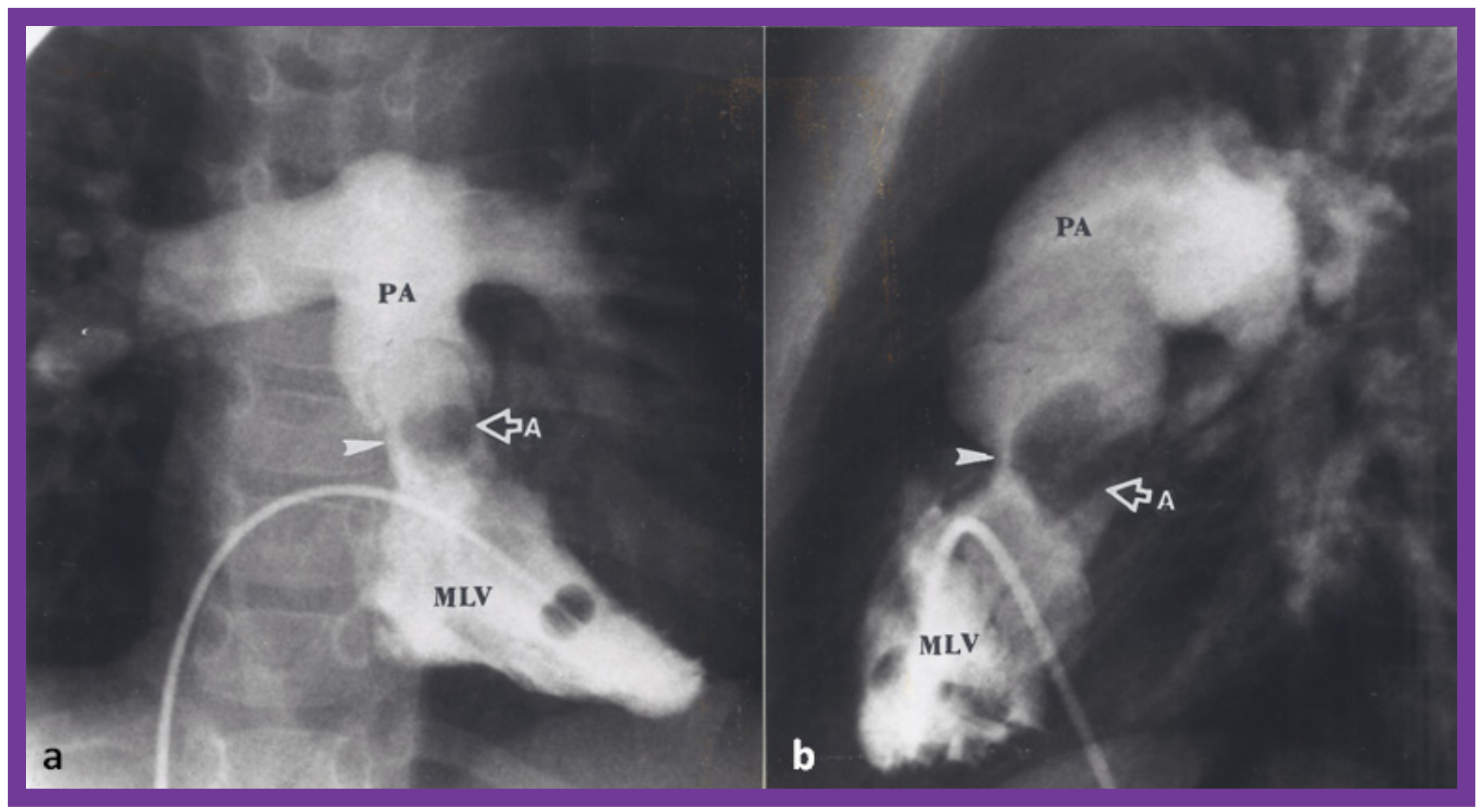

Figure 16: a) Selected frames of a morphologic left ventricular (MLV) angiogram in postero-anterior and; b) Lateral projections, demonstrating a finely trabeculated ventricle with opacification of the pulmonary artery (PA). Note that the pulmonary valve is located posterior and inferior to and rightwards from the normal position. The open arrow points to the radiolucent aneurysm $(A)$ in the sub-pulmonary region. The solid arrow points to a narrow jet of contrast material going from the MLV to the PA, suggesting severe sub-pulmonary obstruction [52].

ght ventricle by angiography following valvotomy for severe pulmonary stenosis with intact ventricular septum [61], role of intracavitary electrocardiography in the diagnose Ebstein's anomaly of the left atrioventricular valve in children with congenital corrected transposition of the great arteries [18], demonstration of utility of pulmonary vein wedge angiography in visualization of obstructed pulmonary arteries (Figure 13) [62], growth phenomenon as a mechanism for development of kinking of the right pulmonary artery following Waterston anastomosis (Figure 14) [63], and documentation of a new complication of the Waterston anastomosis, namely false aneurysm of the right pulmonary artery [64].

The presentation also included manifestation of non-opacification of patent ductus arteriosus in patients with large proximal shunts [65], outcome of intra-arterial injection of heparin on the complications associated with percutaneous arterial catheterization [66], depiction of a new technique of left ventricular and aortic catheterization and angiography via a patent ductus arteriosus $[67,68]$, value of balloon occlusion aortography in demonstrating proximal structures and aorto-pulmonary collateral vessels (Figure 15) [69], and documentation of aneurysms of the membranous ventricular septum resulting in pulmonary outflow tract obstruction in congenitally corrected transposition of the great arteries both in patients with levocardia (Figure 16) [52] and those with dextrocardia $[53,54]$.

\section{References}

1. Rao PS (2020) Pediatric Cardiology: How it has evolved over the last 50 years. Cambridge Scholars Publishing. New Castle upon Tyne, United Kingdom.

2. Liebman J, Lee MH, Rao PS, Mackay W (1973) Quantitation of the normal Frank and McFee Parungao orthogonal electrocardiogram in the adolescent. Circulation 48: 735-752.

3. Rao PS, Monarrez CN (1981) Electrocardiographic differentiation of posterobasal left ventricular hypertrophy from right ventricular hypertrophy. J Electrocardiol 14: 25-30.

4. Rao PS, Thapar MK (1983) The AFORMED phenomenon: A proposed etiology. Am J Cardiol 52: 655.

5. Rao PS, Thapar MK, Harp RJ (1984) Racial variations in electrocardiograms and vectorcardiograms between black and white children and their genesis. $\mathrm{J}$ Electrocardiol 17: 239-252.

6. Rao PS (1985) Racial differences in electrocardiograms and vectorcardiograms between black and white adolescents. J Electrocardiol 18: 309-313.

7. Rao PS, Najjar HN (1987) Congestive cardiomyopathy due to chronic tachycardia: Resolution of cardiomyopathy with antiarrhythmic drugs. Int J Cardiol 17: 216-220.

8. Rao PS, Solymar L (1988) Electrocardiographic changes following balloon dilatation of valvar pulmonic stenosis. J Interventional Cardiol 1: 189-197.

9. Rao PS (2015) Balloon valvuloplasty for pulmonary stenosis. In: Vijayalakshmi IB, Cardiac Catheterization and Imaging (From Pediatrics to Geriatrics). Jaypee Publications, New Delhi, India, 149-174.

10. Rao PS, Leonard T (1976) Polysplenia syndrome. Cardiology Digest 11: 14-22. 
11. Rao PS (1981) Dextrocardia: Systematic approach to differential diagnosis. Am Heart J 102: 389-403.

12. Rao PS (2015) Cardiac malpositions including heterotaxy syndromes. In: Rao PS, Vidyasagar D, Perinatal Cardiology: A Multidisciplinary Approach. Chapter 36, Cardiotext Publishing, Minneapolis, MN

13. Rao PS (2015) Cardiac malposition. In: Gupta P, Menon PSN, Ramji S, Lodha R, PG Textbook of Pediatrics. Jaypee Brothers Medical Publishers (P) Ltd, New Delhi, India, 1807-1816.

14. Rao PS (2018) Cardiac malposition. In: Gupta P, Menon PSN, Ramji S, Lodha R, PG Textbook of Pediatrics. (2 edn), Jaypee Brothers Medical Publishers (P) Ltd., New Delhi, India, 2135-2144.

15. Rao PS, Strong WB (1981) Congenital heart disease. In: Current Therapy 1981. Conn HF, WB Saunders, Philadelphia, PA, 185-209.

16. Rao PS (1989) Congenital heart disease. In: Rakel RE, Conn's Current Therapy, 1989. WB Saunders, Philadelphia, PA, 201-213.

17. Rao PS, Miller MD (1980) Medical Examination Review, Pediatric Cardiology. Medical Examination Publishing Co., Inc., Garden City, New York, USA.

18. Rogers JH Jr, Rao PS (1977) Ebstein's Anomaly of the left atrioventricular valve with congenital corrected transposition of the great arteries. Diagnosis by intracavitary electrocardiography. Chest 72: 253-256.

19. Kulangara RJ, Boineau JP, Rao PS (1982) Electrovectorcardiographic features of tricuspid atresia. In: Rao PS, Tricuspid Atresia. Chapter 9, Futura Publishing Co., Mount Kisco, New York.

20. Rao PS, Kulangara RJ, Boineau JP, Moore HV (1992) Electrovectorcardiographic features of tricuspid atresia. In: Rao PS, Tricuspid Atresia. ( $2^{\text {nd }}$ edn), Chapter 9, Futura Publishing Co, Mt. Kisco, NY.

21. Kulangara RJ, Boineau JP, Moore HV, Rao PS (1981) Ventricular activation and genesis of QRS in tricuspid atresia. Circulation 64: VI-225.

22. Rees AH, Rao PS, Rigby JJ, Miller MD (1978) Echocardiographic estimation of left-to-right shunt in isolated ventricular septal defects. Eur J Cardiol 7: 25-33.

23. Truman AT, Rao PS, Kulungara RJ (1980) Use of contrast echocardiography in diagnosis of anomalous connection of right superior vena cava to left atrium. Br Heart $\mathrm{J} 44$ : 718723.

24. Alpert BS, Rao PS, Moore HV, Covitz W (1981) Surgical correction of anomalous right superior vena cava to the left atrium. J Thorac Cardiovasc Surg 82: 301-305.

25. Covitz W, Rao PS, Strong WB, Reyes L (1982) Echocardiographic assessment of the aortic root in syndromes with left ventricular hypoplasia. Pediatr Cardiol 2: 19-23.

26. Rao PS, Kulangara RJ (1982) Echocardiographic evaluation of global left ventricular performance in infants and children. Indian Pediatr 19: 21-32.

27. Rao PS (1983) Non-invasive evaluation of left ventricular function in infants and children. Saudi Med J 4: 195-209.

28. Covitz W, Rao PS (1982) Non-invasive evaluation of patients with tricuspid atresia (Roentgenography, Echocardiography, and Nuclear Angiography). In: Rao PS, Tricuspid Atresia. Futura Publishing Co., Mount Kisco, New York, 127-145.
29. Rao PS, Andaya WG, Whisennand HH (1983) Contrast echocardiography in the differential diagnosis of hypoxemia following open heart surgery. Annals of Saudi Medicine 3: $121-124$

30. Rao PS, Thapar MK, Haggard RJ, Strong WB (1983) Left ventricular muscle mass by m-mode echocardiography in children. J Cardiovasc Ultrasonography 2: 381-389.

31. Rao PS, Thapar MK (1984) Influence of race and sex on echocardiographic measurements in children. J Cardiovasc Ultrasonography 3: 75-82.

32. Balfour IC, Covitz W, Davis H, Rao PS, Strong WB, et al. (1984) Cardiac size and function in Children with Sickle Cell Anemia. Am Heart J 108: 345-350.

33. Rao PS, Andaya WG (1986) Chronic afterload reduction in infants and children with primary myocardial disease. $J$ Pediatr 108: 530-534.

34. Rao PS (1986) Value of echo-Doppler studies in the evaluation of the results of balloon pulmonary valvuloplasty. $J$ Cardiovasc Ultrasonography 5: 309-314.

35. Rao PS (1987) Doppler ultrasound in the prediction of transvalvar pressure gradients in patients with valvar pulmonary stenosis. Int J Cardiol 15: 195-203.

36. Rao PS (1988) Doppler echocardiography in non-invasive diagnosis of heart disease in infants and children. Indian $\mathrm{J}$ Pediatr 55: 80-95.

37. Rao PS (1988) Value of echo-Doppler studies in the evaluation of the results of balloon angioplasty of aortic coarctation. J Cardiovasc Ultrasonography 7: 215-220.

38. Rao PS, Carey P (1989) Doppler ultrasound in the prediction of pressure gradients across aortic coarctation. Am Heart J 118: 299-307.

39. Wilson AD, Rao PS, Aeschlimann S (1990) Normal fetal foramen flap and transatrial Doppler velocity pattern. J Am Soc Echocardiogr 3: 491-494.

40. Rao PS, Langhough R (1991) Relationship of echocardiographic, shunt flow, and angiographic size to the stretched diameter of the atrial septal defect. Am Heart J 122: 505508 .

41. Rao PS, Langhough R, Beekman RH, Lloyd TR, Sideris EB (1992) Echocardiographic estimation of balloon-stretched diameter of secundum atrial septal defect for transcatheter occlusion. Am Heart J 124: 172-175.

42. Reddy SC, Rao PS, Ewenko J, Koscik R, Wilson AD (1995) Echocardiographic predictors of success of catheter closure of atrial septal defect with the buttoned device. Am Heart J 129: 76-82.

43. Reddy SC, Chopra PS, Rao PS (1995) Mixed type total anomalous pulmonary venous connection: Echocardiographic limitations and angiographic advantages. Am Heart J 129: 1034-1038.

44. Rao PS, Ende DJ, Wilson AD, Smith PA, Chopra PS (1995) Follow-up results of transcatheter occlusion of atrial septal defects with buttoned device. Can J Cardiol 11: 695-701.

45. Singh GK, Marino CJ, Rao PS (1996) Left heart outflow obstruction, aortic stenosis and coarctation of the aorta: An echocardiographic assessment. Pediatr Ultrasound Today 1: 61-76.

46. Singh GK, Marino C, Rao PS (1996) Ultrasound as an adjunct to cardiac interventions in pediatric patients. J Invasive Cardiol 8: 341-349.

47. Singh GK, Marino CJ, Rao PS (1997) Echocardiographic 
evaluation of coarctation of the aorta in adults. Cardiac UItrasound Today 3: 111-124.

48. Jureidini SB, Hormann JW, Williams J, Ferdman B, Rao PS (1998) Morphometric assessment of the innominate vein in the prediction of persistent left superior vena cava. J Am Soc Echocardiogr 11: 372-376.

49. Jureidini SJ, Marino C, Rao PS, et al. (1998) Transthoracic color and pulsed Doppler echocardiographic assessment of normal coronary artery flow in children. J Am Soc Echocard 11: $409-420$

50. Jureidini SB, Marino CJ, Singh GK, Balfour IC, Rao PS, et al. (2003) Aberrant coronary arteries: A reliable echocardiographic screening method. J Am Soc Echocardiogr 16: 756-763.

51. Rao PS, Galal O, Patnana M, Buck SH, Wilson AD (1998) Results of three-to-10-year follow-up of balloon dilatation of the pulmonary valve. Heart 80: 591-595.

52. Reddy SC, Chopra PS, Rao PS (1997) Aneurysm of the membranous ventricular septum resulting in pulmonary outflow tract obstruction in congenitally corrected transposition of the great arteries. Am Heart J 133: 112-119.

53. Yarrabolu TR, Thapar MK, Rao PS (2014) Subpulmonary obstruction due to aneurysmal ventricular septum in a patient with congenitally corrected transposition of the great arteries and dextrocardia. Congenital Cardiology Today 12 : $1-8$.

54. Yarrabolu TR, Thapar MK, Rao PS (2015) Subpulmonary obstruction from aneurysmal ventricular septum in a child with dextrocardia and congenitally corrected transposition of the great arteries. Tex Heart Inst J 42: 590-592.

55. Rao PS, Sissman NJ (1971) The relationship of pulmonary venous wedge to pulmonary arterial pressures. Circulation 44: 565-594.

56. Rao PS (1973) The femoral route for cardiac catheterization of infants and children. Chest 63: 239-241.

57. Rao PS, Molthan ME (1973) Systemic venous anomalies and partial heterotaxia with normal heart. Am J Dis Child 125: $749-752$.
58. Rao PS, Awa S, Linde LM (1973) Role of kinetic energy in pulmonary valvar pressure gradients. Circulation 48: 65-73.

59. Rao PS, Linde LM (1974) Pressure and energy in the cardiovascular chambers. Chest 66: 176-178.

60. Rigby JJ, Rao PS (1975) Cardiac catheterization in infancy and childhood. Paediatrician 4: 343-455.

61. Rao PS, Liebman J, Borkat G (1976) Right ventricular growth in a case of pulmonic stenosis with intact ventricular septum and hypoplastic right ventricle. Circulation 53: 389394.

62. Rao PS (1978) Value of pulmonary vein wedge angiography in visualization of obstructed ipsilateral pulmonary artery. Cardiovasc Radiol 1: 151-152.

63. Rao PS, Ellison RG (1978) The cause of kinking of the right pulmonary artery in Waterston Anastomosis. A Growth Phenomenon. J Thorac Cardiovasc Surg 76: 126-129.

64. Monarrez CN, Rao PS, Moore HV, Strong WB (1979) False aneurysm of the right pulmonary artery. New complication of aorta-right pulmonary artery anastomosis. J Thorac Cardiovasc Surg 77: 738-741.

65. Rao PS, Thapar MK, Strong WB (1978) Nonopacification of patent ductus arteriosus by aortography in patients with large ventricular septal defects. Angiology 29: 888-897.

66. Rao PS, Thapar MK, Rogers JH Jr, Strong WB, Lutcher CL, et al. (1981) Effect of intraarterial injection of heparin on the complications of percutaneous arterial catheterization in infants and children. Cathet Cardiovasc Diagn 7: 235-246.

67. Mardini MK, Rao PS (1983) Aortic arch angiography in patients with patent ductus arteriosus: A new technique. Pediatr Cardiol 4: 53-54.

68. Mardini MK, Rao PS (1983) Left ventricular and aortic catheterization and angiography via a patent ductus arteriosus: A new technique. Cathet Cardiovasc Diagn 9: 89-95.

69. Rao PS (1985) Descending aortography with balloon inflation: A technique for evaluating the size of persistent ductus arteriosus in infants with large proximal left to right shunts. Br Heart J 54: 527-532. 